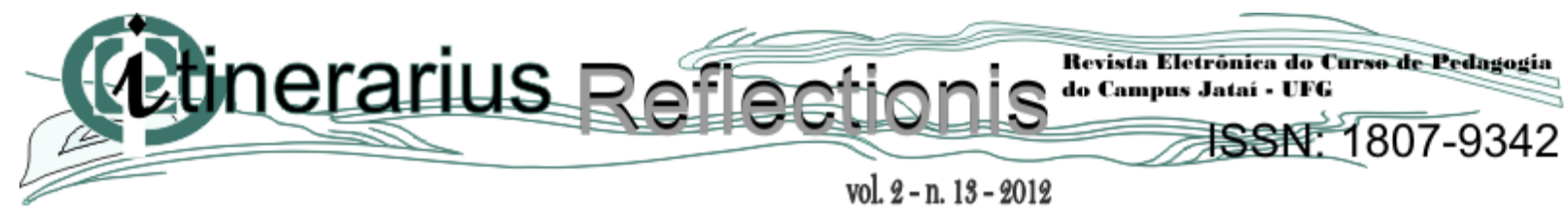

\title{
O MÉTODO DA ECONOMIA POLÍTICA - Breves considerações sobre o método dialético materialista de Karl Marx
}

José Sílvio de Oliveira. Universidade Federal de Goiás Campus Jataí. oliveirajsilvinho@ hotmail.com

\begin{abstract}
RESUMO: Ao sintetizar algumas linhas mais gerais sobre a questão do método dialético materialista, de Karl Marx, nosso objetivo é verificar, brevemente, como ele elabora suas análises ao investigar o modo de produção da sociedade capitalista. O texto-chave que propomos para as nossas breves considerações faz parte de um esboço que Karl Marx suprimiu da introdução geral, $O$ método da Economia Política, conforme ele mesmo afirma no prefácio do livro Para a Crítica da Economia Política, publicado em 1854. Ressalta Marx: "Suprimo uma introdução geral que tinha esboçado porque, refletindo mais fundo, me parece prejudicial toda antecipação de resultados ainda a comprovar..." Para contribuição dessas linhas introdutórias, juntamente com o texto referido, incluiremos outros, como: o Prefácio e Posfácio do livro $O$ Capital; Manuscritos Econômico-Filosóficos; e a Introdução à Crítica da Economia. Considerando a riqueza teórica e a complexidade do texto em estudo, nossas breves considerações podem ser traduzidas em duas perguntas. Primeira: quais são as críticas que Karl Marx faz aos economistas do século XVIII, e por que o faz? Segunda: do ponto de vista da economia política, quais são os resultados alcançados pelo método dialético materialista na dimensão das ciências, tendo como ponto de referência a sociedade capitalista?
\end{abstract}

Palavras-chave: Karl Marx. Método. Economia Política.

\section{THE POLITIC ECONOMIC METHOD - Short considerations about the Karl Marx's materialist dialectic method}

\begin{abstract}
In order to summarize some general information about the question regarding the Karl Marx's materialist dialectic method, our objective is to verify, briefly, the way that he elaborated his analysis when studying the production mode of the capitalist society. The core text that we propose to our brief consideration is part of the draft that Karl Marx suppressed of the general introduction the political economic method, as himself testifies in the preface of the book: to the critic of the political economy, published in 1854. He highlighted: I suppress a general introduction that I had drafted because, in a deeper though, it seems that more harmful all anticipation of results to be proved.... "To the contribution of these introductory lines, in addition
\end{abstract}




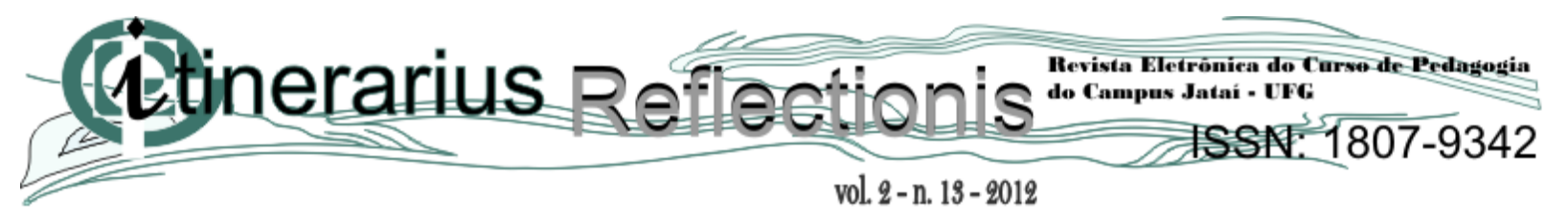

to the referred text, we will include others such as: Preface and afterword of the book the Capital; Philosophical-Economical Manuscript; and the Introduction to the Economy Critic. Considering all theory richness and the complexity of the text in study, our brief consideration can be translated in two questions. First: which are the critics that Kark Marx did to the economist of the XVIII century, and why did he do? Second: from the political economy point of view, which are the results reached by the materialist dialectic method in the dimension of science, having as reference, the capitalist society?

Key-words: Karl Marx. Method. Political Economy.

\section{O MÉTODO DA ECONOMIA POLÍTICA - Breves considerações sobre o método dialético materialista de Karl Marx}

Do ponto de vista dos procedimentos metodológicos, Karl Marx entende que o objeto precisa ser investigado em todas suas formas de evolução - o trabalho do pesquisador deve rastrear e detalhar intimamente os nexos internos que se ligam e interligam sua estrutura. Ao expor seu método, Karl Marx faz mais do que uma simples exposição: apresenta os resultados de suas pesquisas; de forma sistematizada elabora e analisa as categorias que traduzem o problema da sociedade capitalista; embora não diretamente, como faz na Introdução à Crítica da Economia Política, tece críticas contundentes aos métodos dos economistas do século XVIII, e ao mesmo tempo vai abrindo as portas para a consolidação de um novo caminho para as pesquisas, nasce um novo método científico. O método de Karl Marx difere do método de Hegel, como lê-se no Posfácio da Segunda Edição do Livro O Capital: "Por sua fundamentação, meu método dialético não só difere do hegeliano, mas é também a sua antítese direta." 1 Já no pósfácio da primeira edição dessa mesma obra ele vai falar e dizer claramente seu objeto de pesquisa, afirma Marx. Que sua intenção é estudar "[...] o modo de produção capitalista e suas relações correspondentes

\footnotetext{
${ }^{1}$ MARX, Karl. O capital: crítica da economia política. Trad. Regis Barbosa e Flávio Khote. São Paulo: Abril Cultural, 1983. p. 20. (Os Economistas).
} 


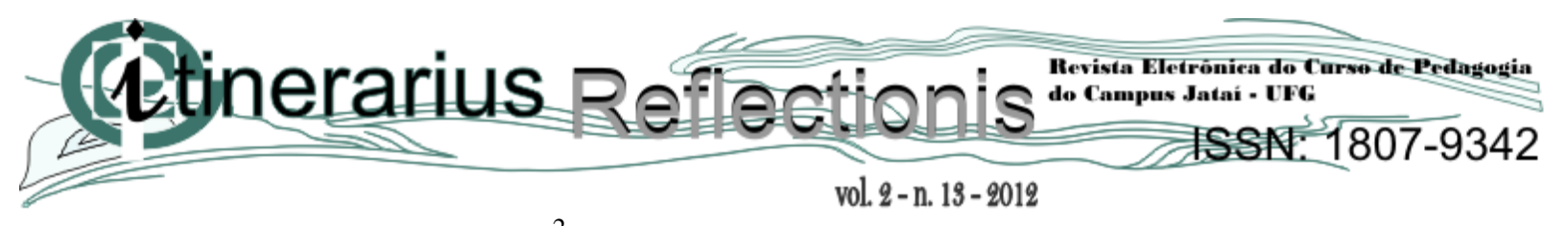

de produção e circulação" 2 , seu método tem o objetivo de realizar e conseguir apreender a concreticidade do concreto. Para ele, a realidade não se dá a conhecer imediatamente, e isso é o suposto objeto da investigação da dialética. Ao investigar seu objeto, quer conhecer o concreto para além de sua aparência, de sua forma. Quer reconhecer o significado do fato, do dado empírico que se apresenta.

Previamente, é necessário afirmar que Karl Marx não trabalhou sistematicamente a questão do método. O método não é, para ele, a questão fundamental, ou o ponto que se deve olhar primeiro. O que se pode afirmar é que ele o aplicou.

Nós sabemos que Marx pouquíssimas vezes se deteve numa discussão metodológica. Quem rastreia, quem conhece a obra de Marx sabe que em pouquíssimos momentos ele dedicou uma atenção autônoma ao tratamento dos problemas metodológicos. Mais uma vez o põe na contra corrente da modernidade. $^{3}$

Logo no início do primeiro parágrafo do texto O Método da Economia Política, Karl Marx transcreve dois modelos de métodos de pesquisa. O primeiro a ser descrito é o método dos economistas ingleses do século XVIII; no segundo, Karl Marx faz a exposição de seu método - o método dialético. Em relação aos pesquisadores da economia inglesa, Marx tece críticas e entende que a economia política da sociedade burguesa é a chave para compreender a sociedade antiga, entretanto, "Porém, não conforme o método dos economistas que fazem desaparecer todas as diferenças históricas e vêem a forma burguesa em todas as suas formas de sociedade." ${ }^{4}$ Do ponto de vista mais amplo, o problema emergente da economia burguesa está vinculado à impossibilidade de distinguir a forma especificamente social do trabalho que cria valor, e se

\footnotetext{
${ }^{2}$ Idem. p. 12

${ }^{3}$ NETTO, José Paulo. Relendo a teoria marxista da história. In: SAVIANI, Dermeval. LOMBARDI, José Claudinei. SANFELICE, José Luís. (Orgs.) História e história da educação. 2000. p. 56.

${ }^{4}$ MARX, Karl. Para a crítica da economia política. In: Manuscritos-econômico-filosóficos. Seleção de textos de José Arthur Giannotti. Traduções de José Carlos Bruni. (Manuscritos econômico-filosóficos. Edgar Malagodi. (Para a Crítica da Economia Política). José Arthur Giannotti e Walter Rehfed. O Rendimento e suas Fontes e Leandro Konder (Salário, Preço, e Lucro). Sãol Paulo: Abril Cultural. 1978.p.120. (Os Pensadores).
} 


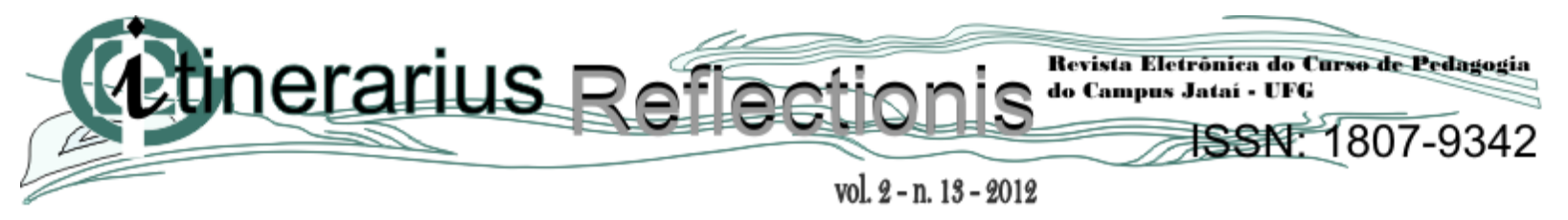

efetiva numa forma de produção específica e determinada historicamente, do trabalho em geral. "Seria, pois, impraticável e errôneo colocar as categorias econômicas na ordem segunda a qual tiveram historicamente uma ação determinante." 5 A forma pela qual as categorias econômicas foram analisadas pelos pesquisadores da sociedade burguesa são percebidas inversamente, ou seja, contrário ao seu método.

Ao descartar o caminho percorrido pelos economistas, Marx critica os métodos econômicos e, seja pelas pequenas ou grandes robinsonadas, na Introdução à Crítica da Economia Política, ele expressa: "Indivíduos produzindo em sociedade, portanto a produção dos indivíduos determinada socialmente é por certo o ponto de partida." ${ }^{6} \mathrm{O}$ método adotado pelos pesquisadores da economia política analisa o indivíduo como um produtor isolado e não como um indivíduo produto de um resultado histórico. Da mesma forma, Marx vai criticar esses economistas por também não perceberem a dimensão da totalidade histórica do processo de produção. Eles não enxergam as esferas da produção, da distribuição, da troca, do consumo como que integradas e integrantes de uma totalidade. Tomadas assim, nesse sentido, isolando essas esferas, a produção se converte numa forma natural e independente da história. Sendo assim, a economia política não pode compreender a raiz da questão do trabalho que se constitui sob a forma de produção específica. Ao refletir sobre os pressupostos e categorias da economia política (que são, a saber: a propriedade privada, a separação entre trabalho e capital, capital e terra, salários, o lucro do capital, a questão da divisão do trabalho, e o conceito de valor), Karl Marx afirma no livro Manuscritos Econômico- Filosóficos "A partir da própria economia política, em suas próprias palavras, expusemos que o trabalhador desce até o nível da mercadoria, e de miserabilíssima mercadoria." 7 A economia política não faz distinção entre capital, terra e

\footnotetext{
${ }^{5}$ Idem, p. 122.

${ }^{6}$ MARX, Karl. Para a crítica da economia política. In: Manuscritos-econômico-filosóficos. Seleção de textos de José Arthur Giannotti. Traduções de José Carlos Bruni. (Manuscritos econômico-filosóficos. Edgar Malagodi. (Para a Crítica da Economia Política). José Arthur Giannotti e Walter Rehfed. O Rendimento e suas Fontes e Leandro Konder (Salário, Preço, e Lucro). Sãol Paulo: Abril Cultural. 1978. p103. (Os Pensadores).

${ }^{7}$ Karl Marx. MARX, Karl. Manuscritos Econômico-Filosóficos. Martin Claret: São Paulo. 2001. (Coleção A Obra Prima de cada Autor). 2001. p. 110.
} 


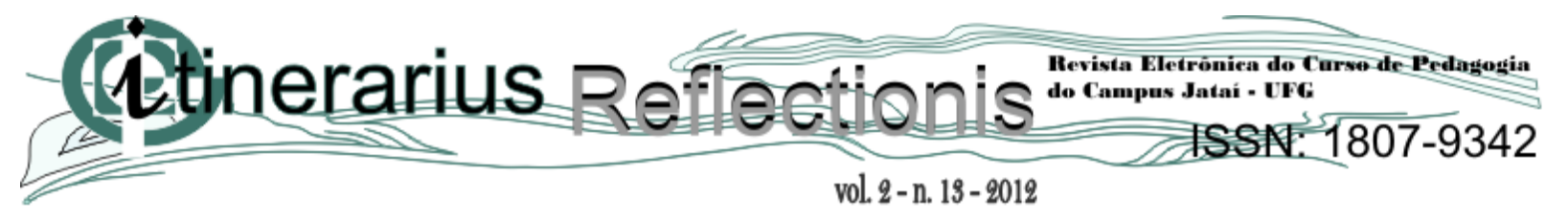

trabalho. Os fatores lucro, renda e salário, que são independentes entre si, de certa forma interagem ricamente na criação do valor.

As críticas de Karl Marx caminham nessa direção, tanto para Ricardo como para Smith. O próprio conceito de trabalho acumulado e objetivado invalida a possibilidade de os teóricos da economia burguesa compreenderem o capital. "Os economistas burgueses viam relações entre objetos (troca de mercadorias por outras), Marx descobriu relações entre pessoas." 8 Nessa perspectiva, pode dizer-se que são indivíduos, pessoas, que na verdade são personificações de categorias econômicas e, portanto, são portadoras de relações, de processos de um jogo de classes, de interesses.

Ao analisar o modo da produção da sociedade capitalista, Marx identifica, como um dos pontos fundamentais, a mercadoria como um produto capaz de satisfazer as nossas necessidades básicas, devido às suas peculiaridades. No livro o Capital, pode-se ler: “À primeira vista a mercadoria parece uma coisa trivial, evidente. Analisando-a vê-se que ela é uma coisa complicada, cheia de sutilezas metafísicas e manhas teológicas." 9 Por sua vez, a economia política vai esconder, vai ocultar a alienação quando investiga a relação imediata entre trabalho e trabalhador. Para Karl Marx, é preciso entender todo o sistema de alienação. A mercadoria esconde o caráter social da produção, e assim o homem vende o que tem de mais precioso, sua força de trabalho.

No prefácio do livro Para a Crítica da Economia Política, Marx fala que sua investigação geral desembocou num resultado contrário ao trabalho de Hegel e de todos os economistas franceses e ingleses do século XVIII. O fio condutor de seu estudo pode ser assim descrito:

\footnotetext{
8 LÉNINE, V. I. As três fontes e as três partes constitutivas do marxismo. Disponível em http://www.marxists.org/portugues/lenin/1913/03/tresfont.htm. Acesso em nov. 2011. p.3.

${ }^{9}$ Karl Marx. O capital: crítica da economia política. Volume I Livro Primeiro. O processo de produção do capital. Tomo I. Prefácio e Capítulos I a XII. Apresentação de Jacob e Coordenação e revisão de Paul Singer. Tradução de Regis Barbosa e Flávio R. Kothe. São Paulo: Abril Cultural. 1983.p.70. (Os Economistas).
} 


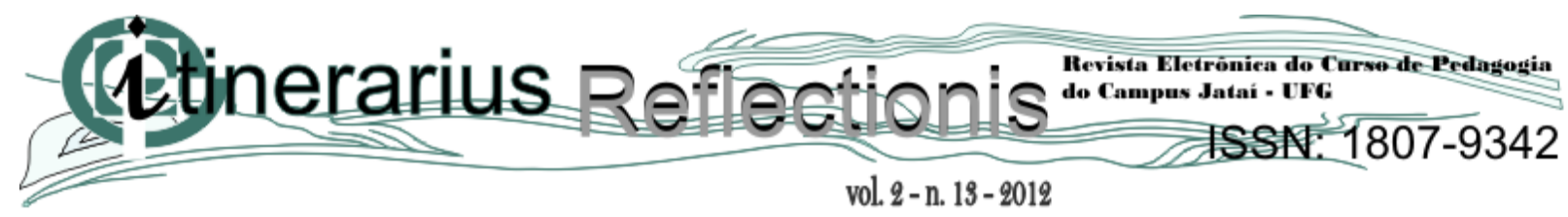

O resultado geral a que cheguei e que, uma vez obtido, serviu-me de fio condutor aos meus estudos, pode ser formulado em poucas palavras: na produção social da sua vida os homens entram em determinadas relações, necessárias, independentes de sua vontade, relações de produção que correspondem a uma determinada etapa de desenvolvimento das suas forças produtivas materiais. A totalidade destas relações de produção forma a estrutura econômica da sociedade, a base real sobre a qual se ergue uma superestrutura jurídica e política, e à qual correspondem determinadas formas da consciência social. O modo de produção da vida material é que condiciona o processo da vida social, política e espiritual. Não é a consciência dos homens que determina seu ser, mas, inversamente, o seu ser social que determina a sua consciência. $\mathrm{O}$ modo de produção da vida material condiciona o processo em geral de vida social, político e espiritual. Não é a consciência dos homens que determina o seu ser, mas, ao contrário, é o seu ser social que determina sua consciência. ${ }^{10}$

Ao fazer a exposição de seu método, Karl Marx deixa transparecer nitidamente o caminho que percorreu, que é exatamente o caminho inverso do caminho que percorreram os pesquisadores da economia política. Os economistas não conseguiram apreender o conteúdo essencial da sociedade. Ao dar início ao seu percurso, Marx também parece concordar com a trilha que percorreram os economistas, pois, afirma ele: "Parece que o correto é começar pelo real e pelo concreto, que são a pressuposição prévia e efetiva; assim, em Economia, por exemplo, começar-se ia pela população, que é a base e o sujeito do ato social de produção como um todo." ${ }^{11} \mathrm{O}$ caminho até então parecia seguro. Entretanto, a partir de uma observação mais perspicaz sobre a questão, Marx abre uma nova possibilidade de apreender seu objeto. O caminho que até então se mostrava seguro parece não ter volta. Começar a pesquisa pela população pode parecer interessante, porém expressa Karl Marx: “A população é uma abstração, se desprezarmos as classes que a compõem. Por seu lado, estas classes são uma palavra vazia de sentido se

\footnotetext{
${ }^{10}$ Karl Marx. Prefácio da crítica da economia política. In: Manuscritos-econômico-filosóficos. Seleção de textos de José Arthur Giannotti. Traduções de José Carlos Bruni. (Manuscritos econômico-filosóficos. Edgar Malagodi. (Para a Crítica da Economia Política). José Arthur Giannotti e Walter Rehfed. O Rendimento e suas Fontes e Leandro Konder (Salário, Preço, e Lucro). São| Paulo: Abril Cultural. 1978. p.129-130. (Os Pensadores).

${ }^{11}$ MARX, Karl. Para a crítica da economia política In: Manuscritos-econômico-filosóficos. Seleção de textos de José Arthur Giannotti. Traduções de José Carlos Bruni. (Manuscritos econômico-filosóficos. Edgar Malagodi. (Para a Crítica da Economia Política). José Arthur Giannotti e Walter Rehfed. O Rendimento e suas Fontes e Leandro. (Os Pensadores) Konder (Salário, Preço, e Lucro). São| Paulo: Abril Cultural. 1978.p. 116. (Os Pensadores)
} 


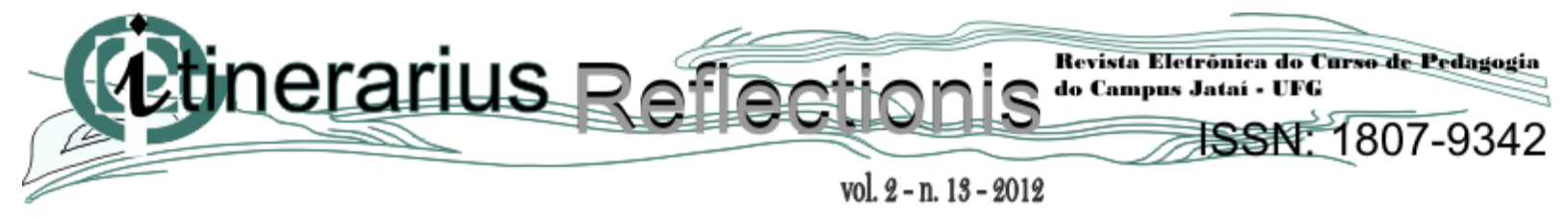

ignorarmos os elementos em que repousam, por exemplo: o trabalho assalariado, o capital etc." 12 Marx enfatiza que, nesse primeiro percurso dos economistas, teríamos uma representação caótica e inadequada do todo, da totalidade, uma vez que, se a população é o real do qual se parte para trilhar a economia política, o resultado é impróprio, pois a pesquisa não evidenciou nem desvelou as determinações que constituem a população. Marx afirma que os economistas, após terem feito tal percurso, "terminam sempre por descobrir, por meio da análise, certo número de relações gerais abstratas que são determinantes, tais como a divisão do trabalho, o dinheiro, o valor, etc." ${ }^{13}$ Por isso Karl Marx faz o caminho inverso, e denomina seu percurso como cientificamente exato: "O último método é manifestamente o método cientificamente exato." 14 Por que Karl Marx diz isso? Exatamente porque seu percurso agarra o real, a matéria, o dado empírico. O real é histórico, é matéria, é uma realidade complexa que se configura como uma síntese. Afirma ele, mais uma vez: “O concreto é concreto porque é a síntese de muitas determinações, isto é, é unidade do diverso." 15 Aqui Karl Marx rompe com o método antigo da economia, pois, “[...] o concreto aparece no pensamento como processo de síntese, como resultado e não como ponto de partida, ainda que seja o ponto de partida efetivo e, portanto, o ponto de partida da intuição e da representação." ${ }^{16}$ Dessa forma, para Karl Marx, no primeiro método dos economistas ingleses, “[...] a representação plena volatiliza-se em determinações, no segundo as determinações abstratas conduzem à reprodução do concreto por meio do pensamento." ${ }^{17}$ Ainda, nesse mesmo sentido, no posfácio do livro O Capital, Karl Marx, recordando a dialética hegeliana, diz:

\footnotetext{
${ }^{12}$ Idem. p. 116

13 Idem. p. 116

14 Idem. p. 116.

${ }^{15}$ MARX, Karl. Para a crítica da economia política In: Manuscritos-econômico-filosóficos. Seleção de textos de José Arthur Giannotti. Traduções de José Carlos Bruni. (Manuscritos econômico-filosóficos. Edgar Malagodi. (Para a Crítica da Economia Política). José Arthur Giannotti e Walter Rehfed. O Rendimento e suas Fontes e Leandro. (Os Pensadores) Konder (Salário, Preço, e Lucro). São| Paulo: Abril Cultural. 1978.p. 116. (Os Pensadores)

${ }^{16}$ MARX, Karl. Para a crítica da economia política In: Manuscritos-econômico-filosóficos. Seleção de textos de José Arthur Giannotti. Traduções de José Carlos Bruni. (Manuscritos econômico-filosóficos. Edgar Malagodi. (Para a Crítica da Economia Política). José Arthur Giannotti e Walter Rehfed. O Rendimento e suas Fontes e Leandro. (Os Pensadores) Konder (Salário, Preço, e Lucro). São| Paulo: Abril Cultural. 1978.p. 116. (Os Pensadores).

${ }^{17}$ Idem. 1978, p.116.
} 


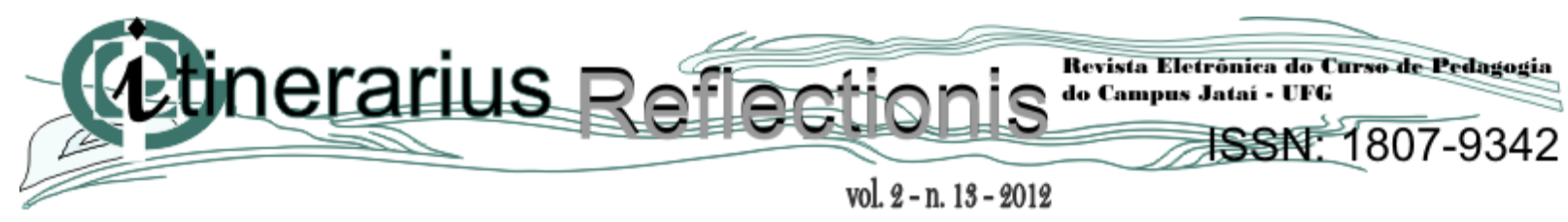

[...] Para Hegel, o processo do pensamento, que ele, sob o nome de ideia, transforma num sujeito autônomo, é o demiurgo real que constitui apenas a sua manifestação externa. Para mim, pelo contrário, o ideal não é nada mais do que o material, transposto e traduzido na cabeça do homem. ${ }^{18}$

Nessa transposição metodológica, Karl Marx retira o lado mistificador da dialética hegeliana. Assim, ele coloca em evidência as contradições da realidade da sociedade capitalista. Como organizador do livro, K. Marx F. Engels, Florestan Fernandes esclarece as questões específicas do método científico. Na introdução desse livro, ele afirma que Karl Marx assume uma identidade própria, moderna, atual sobre o método,

Karl Marx assume uma posição pioneira (e muito moderna) que implicava a condenação do método dominante na 'economia tradicional'. Primeiro ele excluía a teoria gerada pela abstração como fundamento da realidade e punha em seu lugar a teoria produzida pela investigação sistemática e pela interpretação objetiva da realidade. Ou seja, [...] deslocava a fulcro da análise científica, substituindo um 'modelo' abstrato da economia da sociedade burguesa, que a convertia em uma economia tout court, pela economia capitalista e a sociedade burguesa concretas, consideradas como totalidades históricas vivas, dinâmicas interdependentes. Segundo, Karl Marx retirou o método da economia política do reino da mistificação e da fetichização. ${ }^{19}$

Para Fernandes, essa perspectiva, Marx vai superar a teoria gerada pela abstração como fundamento da realidade. Marx passa da representação do movimento da ideia, para a representação do movimento do real, e busca uma teoria que priorize uma interpretação objetiva da realidade, portanto retira a mistificação e o fetiche da economia política. Aqui está uma das maiores contribuições do método dialético materialista. Elevar-se do abstrato ao concreto é, para Marx, uma maneira de apropriar, agarrar o concreto como concreto espiritual, e, portanto, é preciso superar a imediaticidade para encontrar as medições. Ele desvela o lado opressor,

\footnotetext{
${ }^{18}$ Karl Marx. O capital: crítica da economia política. Volume I Livro Primeiro. O processo de produção do capital. Tomo I. Prefácio e Capítulos I a XII. Apresentação de Jacob e Coordenação e revisão de Paul Singer. Tradução de Regis Barbosa e Flávio R. Kothe. São Paulo: Abril Cultural. 1983.p.20. (Os Economistas).

${ }^{19}$ MARX, Karl; ENGELS, Friedrich. Historia. Florestan Fernandes. (Org.). Trad. Florestan Fernandes. $3^{\text {a }}$ ed. São Paulo: Ática. 1989. p.119 (Coleção Grandes Cientistas Sociais).
} 


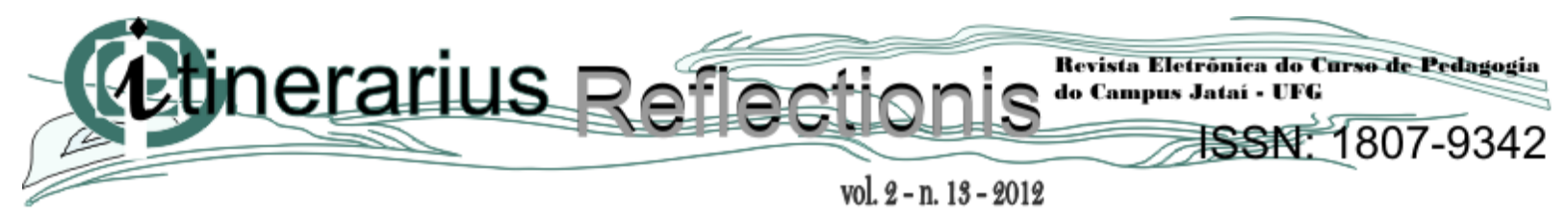

alienante, do sistema capitalista que condiciona e coisifica o trabalhador. O modo das relações de produção condiciona o processo da vida social, política e espiritual do homem.

\section{REFERÊNCIAS}

LÉNINE, V. I. As três fontes e as três partes constitutivas do marxismo. Disponível em http://www.marxists.org/portugues/lenin/1913/03/tresfont.htm. Acesso em: nov. 2011.

MARX, Karl; ENGELS, Friedrich. Historia. Florestan Fernandes. (Org.). Trad. Florestan Fernandes. 3. ed. São Paulo: Ática, 1989. (Coleção Grandes Cientistas Sociais).

MARX, Karl Para a crítica da economia política. In: Manuscritos-econômico-filosóficos. Seleção de textos de José Arthur Giannotti. Traduções de José Carlos Bruni. (Manuscritos econômico-filosóficos. Edgar Malagodi. (Para a Crítica da Economia Política). José Arthur Giannotti e Walter Rehfed. O Rendimento e suas Fontes e Leandro Konder (Salário, Preço, e Lucro). São Paulo: Abril Cultural, 1978. (Os Pensadores).

MARX, Karl. Manuscritos Econômico-Filosóficos. Martin Claret: São Paulo. 2001. (Coleção A Obra Prima de cada Autor). 2001. p. 110.

MARX, Karl. Prefácio da crítica da economia política. In: Manuscritos-econômico-filosóficos. Seleção de textos de José Arthur Giannotti. Traduções de José Carlos Bruni. (Manuscritos econômico-filosóficos. Edgar Malagodi. (Para a Crítica da Economia Política). José Arthur Giannotti e Walter Rehfed. O Rendimento e suas Fontes e Leandro Konder (Salário, Preço, e Lucro). São Paulo: Abril Cultural, 1978. (Os Pensadores).

NETTO, José Paulo. Relendo a teoria marxista da história. In: SAVIANI, Dermeval. LOMBARDI, José Claudinei. SANFELICE, José Luís. (Orgs.) História e história da educação. 2000 . 